\title{
Low temperature atomic layer deposited ZnO photo thin film transistors
}

Feyza B. Oruc, Levent E. Aygun, Inci Donmez, Necmi Biyikli, Ali K. Okyay, and Hyun Yong Yu

Citation: Journal of Vacuum Science \& Technology A: Vacuum, Surfaces, and Films 33, 01A105 (2015); doi: 10.1116/1.4892939

View online: http://dx.doi.org/10.1116/1.4892939

View Table of Contents: http://avs.scitation.org/toc/jva/33/1

Published by the American Vacuum Society

\section{Articles you may be interested in}

High-performance $\mathrm{ZnO}$ thin-film transistors on gate dielectrics grown by atomic layer deposition Applied Physics Letters 88, 123509 (2006); 10.1063/1.2188379

Electrical behavior of zinc oxide layers grown by low temperature atomic layer deposition Applied Physics Letters 92, 023502 (2008); 10.1063/1.2830940

High performance thin film transistor with low temperature atomic layer deposition nitrogen-doped $\mathrm{ZnO}$ Applied Physics Letters 91, 183517 (2007); 10.1063/1.2803219

A comprehensive review of $\mathrm{ZnO}$ materials and devices Journal of Applied Physics 98, 041301 (2005); 10.1063/1.1992666

Wide-bandgap high-mobility $\mathrm{ZnO}$ thin-film transistors produced at room temperature Applied Physics Letters 85, 2541 (2004); 10.1063/1.1790587

High-mobility thin-film transistor with amorphous InGaZnO$O_{4}$ channel fabricated by room temperature rfmagnetron sputtering

Applied Physics Letters 89, 112123 (2006); 10.1063/1.2353811

\section{HDDEN}

\section{Instruments for Advanced Science}

Contact Hiden Analytical for further details: w www.HidenAnalytical.com E info@hiden.co.uk CLICK TO VIEW our product catalogue

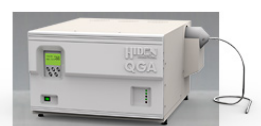

Gas Analysis

dynamic measurement of reaction gas streams

catalysis and thermal analysis

, molecular beam studies

dissolved species probes

, dissolved spectes probes

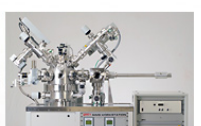

Surface Science

UHVTPD

end point detection in ion beam etch elemental imaging - surface mapping

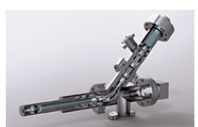

Plasma Diagnostics

plasma source characterization etch and deposition process reaction , kinetic studies analysis of neutral and radical species.

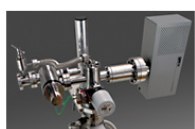

Vacuum Analysis partial pressure measurement and control of process gases , reactive sputter process control , vacuum diagnostics vacuum coating process monitoring 


\title{
Low temperature atomic layer deposited ZnO photo thin film transistors
}

\author{
Feyza B. Oruc, Levent E. Aygun, Inci Donmez, Necmi Biyikli, and Ali K. Okyay ${ }^{\text {a) }}$ \\ Institute of Materials Science and Nanotechnology, Bilkent University, Bilkent, 06800 Ankara, Turkey; \\ UNAM — National Nanotechnology Research Center, Bilkent University, Bilkent, 06800 Ankara, Turkey; \\ and Department of Electrical and Electronics Engineering, Bilkent University, Bilkent, 06800 Ankara, Turkey \\ Hyun Yong Yu \\ The School of Electrical Engineering, Korea University, Seoul 136-701, South Korea
}

(Received 27 May 2014; accepted 1 August 2014; published 20 August 2014)

\begin{abstract}
$\mathrm{ZnO}$ thin film transistors (TFTs) are fabricated on Si substrates using atomic layer deposition technique. The growth temperature of $\mathrm{ZnO}$ channel layers are selected as 80,100, 120, 130, and $250{ }^{\circ} \mathrm{C}$. Material characteristics of $\mathrm{ZnO}$ films are examined using $\mathrm{x}$-ray photoelectron spectroscopy and x-ray diffraction methods. Stoichiometry analyses showed that the amount of both oxygen vacancies and interstitial zinc decrease with decreasing growth temperature. Electrical characteristics improve with decreasing growth temperature. Best results are obtained with $\mathrm{ZnO}$ channels deposited at $80^{\circ} \mathrm{C} ; \mathrm{I}_{\text {on }} / \mathrm{I}_{\text {off }}$ ratio is extracted as $7.8 \times 10^{9}$ and subthreshold slope is extracted as $0.116 \mathrm{~V} /$ dec. Flexible $\mathrm{ZnO}$ TFT devices are also fabricated using films grown at $80^{\circ} \mathrm{C}$. $\mathrm{I}_{\mathrm{D}}-\mathrm{V}_{\mathrm{GS}}$ characterization results showed that devices fabricated on different substrates ( $\mathrm{Si}$ and polyethylene terephthalate) show similar electrical characteristics. Sub-bandgap photo sensing properties of $\mathrm{ZnO}$ based TFTs are investigated; it is shown that visible light absorption of $\mathrm{ZnO}$ based TFTs can be actively controlled by external gate bias. (C) 2014 American Vacuum Society.

[http://dx.doi.org/10.1116/1.4892939]
\end{abstract}

\section{INTRODUCTION}

$\mathrm{ZnO}$ has been gaining significant inertia as a promising material for transparent electronics applications. $\mathrm{ZnO}$ is quickly replacing amorphous silicon (a-Si) based thin film transistor (TFT) technology for flat panel displays, thanks to its outstanding electrical and optical properties. ${ }^{1-3} \mathrm{ZnO}$ is a wide bandgap $\left(\mathrm{E}_{\mathrm{g}} \sim 3.37 \mathrm{eV}\right)$, n-type semiconductor, and it has a natural tendency to form good quality polycrystalline films even deposited at room temperature. ${ }^{4} \mathrm{ZnO}$ TFTs exhibit higher electron mobility compared to traditional a-Si counterparts. $\mathrm{ZnO}$ is also compatible with inexpensive flexible substrates such as plastics owing to low synthesis temperatures. ${ }^{5,6}$ Due to its wide bandgap, $\mathrm{ZnO}$ is transparent in the visible range, a trait not shared by a-Si. ZnO has low light sensitivity that is desired for electronic active matrix of flat panel displays. ${ }^{7}$ Moreover, visible photo-response of $\mathrm{ZnO}$ TFTs is shown to be actively tunable using an external actuation. ${ }^{8}$ There is a significantly vibrant literature on $\mathrm{ZnO}$ channel TFTs deposited with different methods such as physical vapor deposition, chemical vapor deposition, chemical solution deposition, molecular beam epitaxy, and atomic layer deposition (ALD). ${ }^{1-4,9-12}$ The on-to-off current ratios, $\mathrm{I}_{\mathrm{on}} / \mathrm{I}_{\mathrm{off}}$, of these devices range from 10 to $10^{8}$ with reported electron mobility values between 0.031 and $56.43 \mathrm{~cm}^{2} / \mathrm{V}-\mathrm{s}$. $^{2,13-17}$ Among all these techniques, ALD is promising due to the low growth temperature, large area uniformity, precise thickness control, highly conformal deposition, and scalability to roll-to-roll processes. Low temperature processing is very crucial for compatibility with flexible substrates.

In this paper, we present electrical and optical properties of low-temperature ALD grown $\mathrm{ZnO}$ and analyze the effect of channel layer growth temperature on the electrical

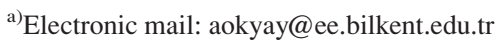

characteristics of bottom-gate ZnO TFTs. We also investigate the optical properties of $\mathrm{ZnO}$ TFTs and show that $\mathrm{ZnO}$ has response to visible light, which can be tuned with applied electrical gate voltage. Due to this significant property, $\mathrm{ZnO}$ thin films may be used in novel applications like smart glasses.

\section{EXPERIMENT}

\section{A. Materials characterization}

Crystal defects such as oxygen vacancies and interstitial zinc are claimed to be responsible for the effective n-type behavior in unintentionally doped $\mathrm{ZnO}$ films. Although there is still debate on the exact mechanisms of defects' contribution to charge carrier concentration, it was shown that low carrier concentrations are achieved with better stoichiometry. In this work, the surface chemical compositions of the ALD-grown $\mathrm{ZnO}$ films are extracted by $\mathrm{x}$-ray photoelectron spectroscopy measurements (XPS-Thermo K-Alpha monochromated high-performance XPS spectrometer). Figure 1(a) shows the survey scan results of $\mathrm{ZnO}$ films grown at different temperatures. Film stoichiometry was determined based on the ratios of the areas under the peaks in measured survey scan data (see Table I). As the growth temperature decreases, films become more stoichiometric. In other words, the amount of both oxygen vacancies and interstitial zinc decrease with decreasing growth temperature. The $\mathrm{O} 1 \mathrm{~s}$ spectrum of films deposited at 80 and $250{ }^{\circ} \mathrm{C}$ are fitted by two subpeaks, which belong to $\mathrm{O}-\mathrm{Zn}$ and $\mathrm{O}-\mathrm{H}$ bonding states [see Fig. 1(b)]. The ratio of areas under these subpeaks is used to extract $\mathrm{O}-\mathrm{H} / \mathrm{O}-\mathrm{Zn}$ ratio for each growth temperature. At $80^{\circ} \mathrm{C}, \mathrm{O}-\mathrm{H} / \mathrm{O}-\mathrm{Zn}$ ratio is extracted as 0.17 ; however, at $250^{\circ} \mathrm{C}$, this ratio decreases down to 0.12 . $\mathrm{Zn} 2 \mathrm{p}$ spectrum confirms the existence of $\mathrm{Zn}-\mathrm{O}$ bonding states and proves that $\mathrm{Zn}$ atoms bind only to $\mathrm{O}$ atoms in this process. 

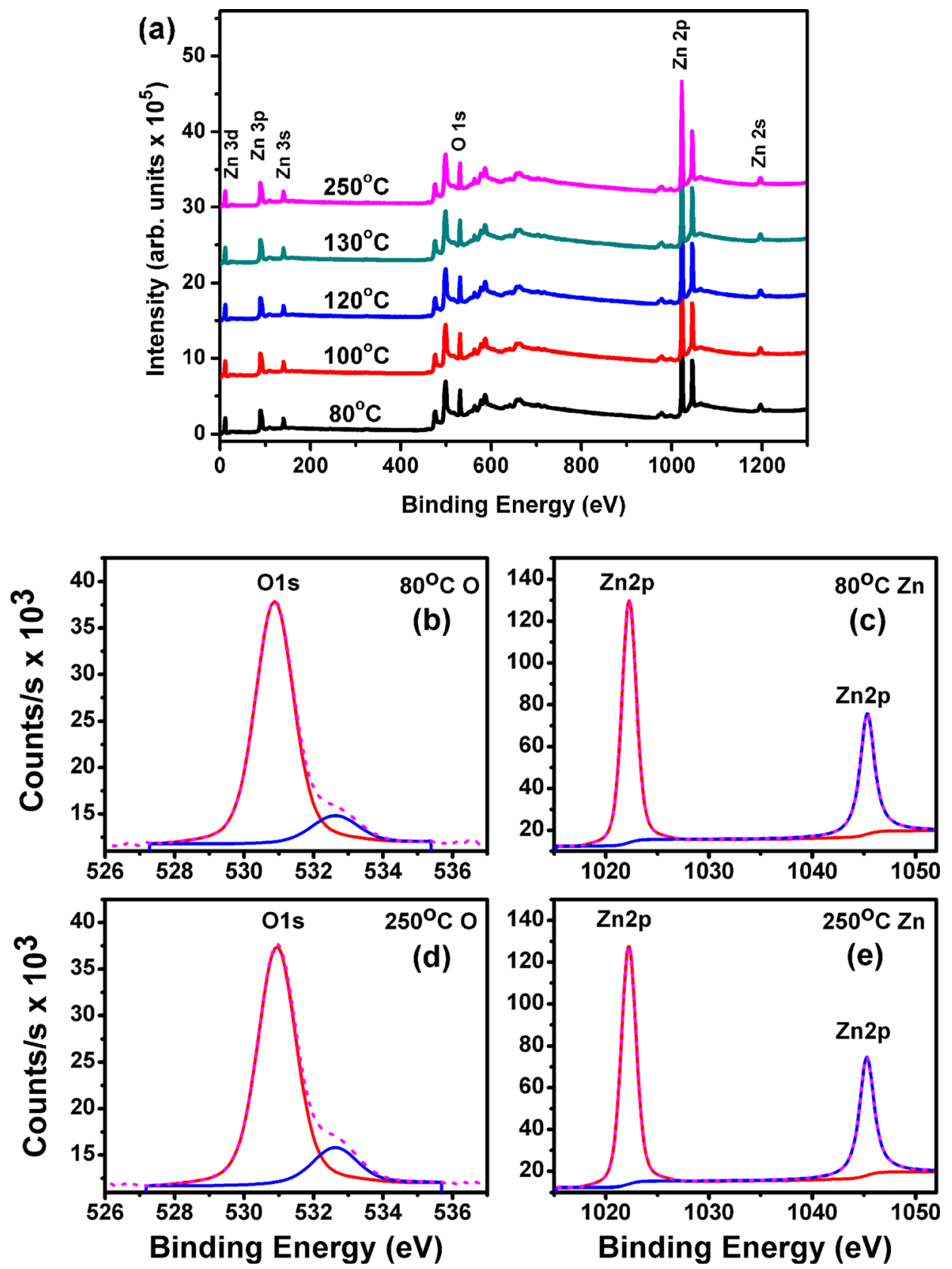

FIG. 1. (Color online) (a) XPS survey scan spectra of $\mathrm{ZnO}$ films, (b)-(e) model fit for high resolution XPS scans of films deposited at $80{ }^{\circ} \mathrm{C}$ [(b) and (c)] and $250^{\circ} \mathrm{C}[(\mathrm{d})$ and (e)]. Dashed curves represent the total measured signal, and the solid curves are O-Zn, O-H, and Zn-O model fit curves.

TABLE I. Stoichiometry analyses of ALD grown $\mathrm{ZnO}$ films deposited at various temperatures.

\begin{tabular}{lrcc}
\hline \hline & \multicolumn{3}{c}{ Atomic percentage ratio (\%) } \\
\cline { 2 - 4 } Growth temperature $\left({ }^{\circ} \mathrm{C}\right)$ & Oxygen & Zinc & O/Zn \\
\hline 80 & 49.88 & 50.12 & 0.995 \\
100 & 49.85 & 50.15 & 0.994 \\
120 & 48.05 & 51.95 & 0.924 \\
130 & 48.57 & 51.43 & 0.944 \\
250 & 48.31 & 51.69 & 0.934 \\
\hline \hline
\end{tabular}

X-ray diffraction (XRD-Panalytical X'pert Pro MRD) measurements indicated that ALD grown $\mathrm{ZnO}$ films possess a hexagonal wurtzite crystal structure with no preferred orientation at lower temperature values. However, at $250^{\circ} \mathrm{C}$, the intensity of (002) orientation increases dramatically. The diffraction maxima occurred at (100), (002), and (101) crystallographic orientations for all $\mathrm{ZnO}$ films (see Fig. 2). XRD results support the natural tendency of $\mathrm{ZnO}$ to form good quality polycrystalline films even at temperatures lower than $100{ }^{\circ} \mathrm{C}$.

\section{B. Device fabrication}

TFT fabrication process starts with the deposition of 210nm-thick $\mathrm{SiO}_{2}$ layer on top of chemically cleaned, highly 


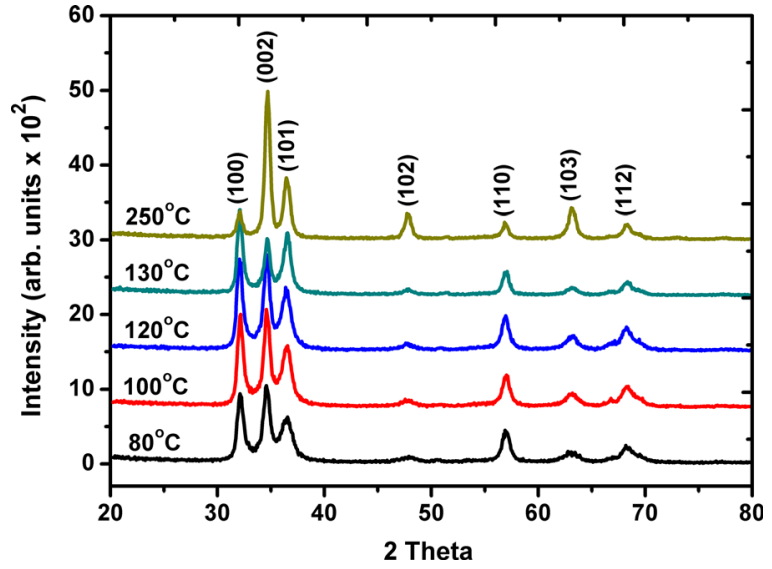

FIG. 2. (Color online) XRD patterns of $\mathrm{ZnO}$ films grown at different temperatures.

doped (10-18 m $\Omega$-cm) p-type (111) Si wafer with a plasma enhanced chemical vapor deposition system. Active device areas are created by a photolithography process followed by wet etching of $\mathrm{SiO}_{2}$ layer using a buffered oxide etch solution $\left(\mathrm{NH}_{4}-\mathrm{HF}, 7: 1\right)$. Highly doped $\mathrm{Si}$ wafer is used as the back-gate electrode. Twenty-nanometer-thick $\mathrm{Al}_{2} \mathrm{O}_{3}$ and 10nm-thick $\mathrm{ZnO}$ layers are both deposited in a Cambridge Nanotech Inc., Savannah S100 ALD system. The growth temperature of $\mathrm{Al}_{2} \mathrm{O}_{3}$ layer is $250^{\circ} \mathrm{C}$. $\mathrm{ZnO}$ channel layer deposition temperatures are $80,100,120,130$, and $250^{\circ} \mathrm{C}$. The precursors for zinc and oxygen are diethylzinc (DEZn) and milli-Q water $\left(\mathrm{H}_{2} \mathrm{O}\right)$, respectively. The processing cycle consists of $15 \mathrm{~ms}$ DEZn pulse and $15 \mathrm{~ms} \mathrm{H}_{2} \mathrm{O}$ pulse, purging times are adjusted according to the growth temperature. $\mathrm{ZnO}$ channels are patterned by wet etching in diluted $\mathrm{H}_{2} \mathrm{SO}_{4}$

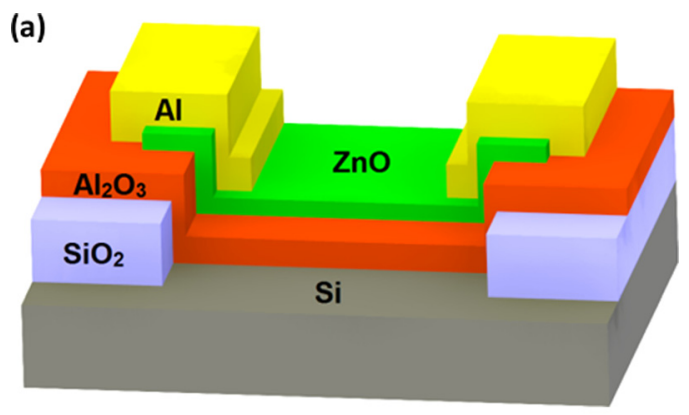

(b)

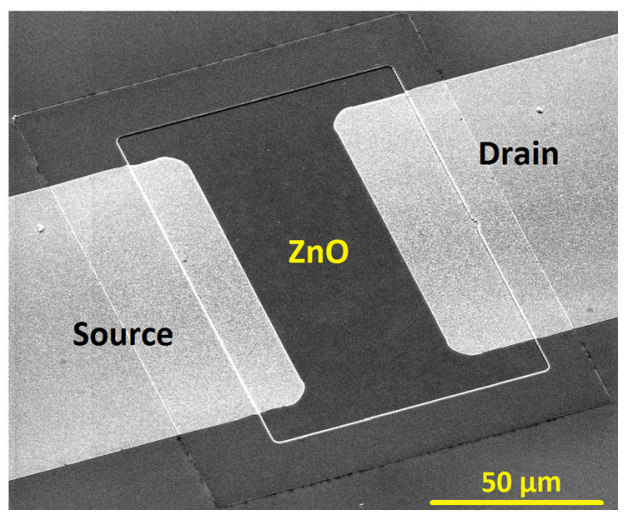

Fig. 3. (Color online) (a) Schematic view of device structure and (b) scanning electron microscope image of a $\mathrm{ZnO}$ TFT. solution. 80-nm-thick Al layer is deposited for electrical contact pads (see Fig. 3).

Fabrication of flexible ZnO TFTs starts with $50 \mathrm{~nm} \mathrm{Al} \mathrm{dep-}$ osition on polyethylene terephthalate (PET) substrates with thermal evaporator and patterned by commercial $\mathrm{Al}$ etchant to create gate contact electrodes. Twenty nanometers thick $\mathrm{Al}_{2} \mathrm{O}_{3}$ and $14 \mathrm{~nm}$ thick $\mathrm{ZnO}$ layers are grown at $80^{\circ} \mathrm{C}$ using the thermal-ALD system. ZnO layer is patterned by a diluted $\mathrm{H}_{2} \mathrm{SO}_{4}$ solution. Fabrication process is completed by $50 \mathrm{~nm} \mathrm{Al}$ deposition using thermal evaporator for source/drain contacts.

\section{RESULTS AND DISCUSSION}

\section{A. Electrical characterization of ZnO TFTs}

Electrical characteristics of ZnO TFTs are measured with a semiconductor parameter analyzer (Keithley 4200-SCS with 4200-CVU) and a DC probe station (Cascade PM-5). $\mathrm{I}_{\mathrm{D}}-\mathrm{V}_{\mathrm{DS}}$ characteristics of devices grown at $80^{\circ} \mathrm{C}$ are shown in Fig. 4(a). Results show that the devices exhibit n-channel enhancement mode MOSFET characteristics as expected.

Table II shows extracted threshold voltage values, subthreshold slopes, $\mathrm{I}_{\text {on }} / \mathrm{I}_{\text {off }}$ ratios, and mobility values of TFTs fabricated on $\mathrm{ZnO}$ channel layers grown at different temperatures. Extrapolation method in the saturation region is implemented on measured $\sqrt{I_{D}}-V_{G}$ characteristics of the devices. Subthreshold slopes are extracted
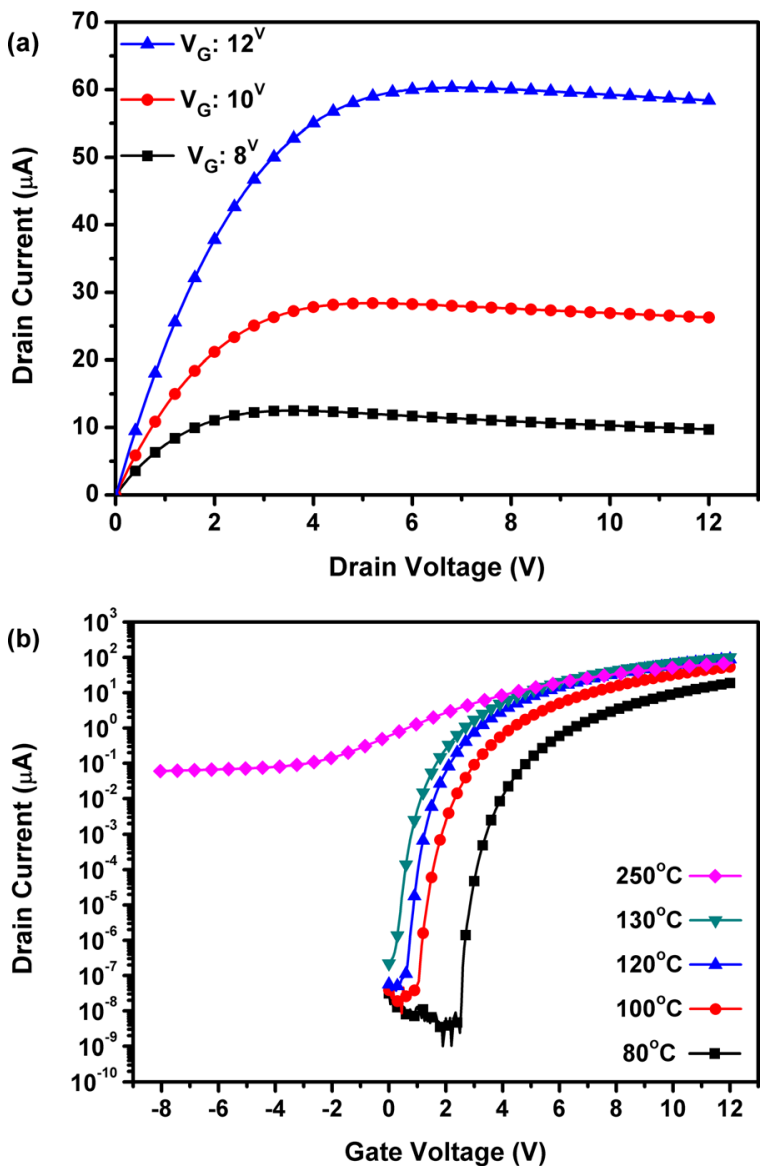

FIG. 4. (Color online) (a) $\mathrm{I}_{\mathrm{D}}-\mathrm{V}_{\mathrm{DS}}$ characteristics of devices grown at $80^{\circ} \mathrm{C}$, (b) $\mathrm{I}_{\mathrm{D}}-\mathrm{V}_{\mathrm{DS}}$ characteristics of devices having $\mathrm{ZnO}$ channel grown at 80, 100, 120, 130 , and $250^{\circ} \mathrm{C}$ with a channel length of $40 \mu \mathrm{m}$ and a channel width of $50 \mu \mathrm{m}$. 
TABLE II. Transistor characteristics with respect to growth temperature.

\begin{tabular}{lcccc}
\hline \hline $\begin{array}{l}\text { Deposition } \\
\text { temperature }\left({ }^{\circ} \mathrm{C}\right)\end{array}$ & $\begin{array}{c}\text { Threshold } \\
\text { voltage (V) }\end{array}$ & $\begin{array}{c}\mathrm{I}_{\text {on }} / \mathrm{I}_{\text {off }} \\
\text { ratio }\end{array}$ & $\begin{array}{c}\text { Subthreshold } \\
\text { slope }(\mathrm{V} / \mathrm{dec})\end{array}$ & $\begin{array}{c}\text { Mobility } \\
\left(\mathrm{cm}^{2} / \mathrm{V} \mathrm{s}\right)\end{array}$ \\
\hline 250 & -0.7 & $10^{3}$ & 3 & 23 \\
130 & 1.58 & $4.5 \times 10^{8}$ & 0.165 & 15.91 \\
120 & 2.09 & $1.8 \times 10^{9}$ & 0.140 & 14.9 \\
100 & 2.8 & $2 \times 10^{9}$ & 0.170 & 8.94 \\
80 & 4.3 & $7.8 \times 10^{9}$ & 0.116 & 3.96 \\
\hline \hline
\end{tabular}

from $\log \left(\mathrm{I}_{\mathrm{D}}-\mathrm{V}_{\mathrm{G}}\right)$ characteristics of the devices using the formula of $\mathrm{dV}_{\mathrm{G}} / \mathrm{dLog}\left(\mathrm{I}_{\mathrm{D}}\right)$. Device mobility values were calculated using output $I_{D}-V_{D}$ characteristics. Oxide capacitance is calculated using the equation

$$
\begin{aligned}
& \mathrm{C}_{\mathrm{ox}}=\varepsilon_{\mathrm{ox}} / \mathrm{t}_{\mathrm{ox}}, \\
& \mathrm{C}_{\mathrm{ox}}=\varepsilon_{0} \cdot \varepsilon_{\mathrm{r}} / \mathrm{t}_{\mathrm{ox}},
\end{aligned}
$$

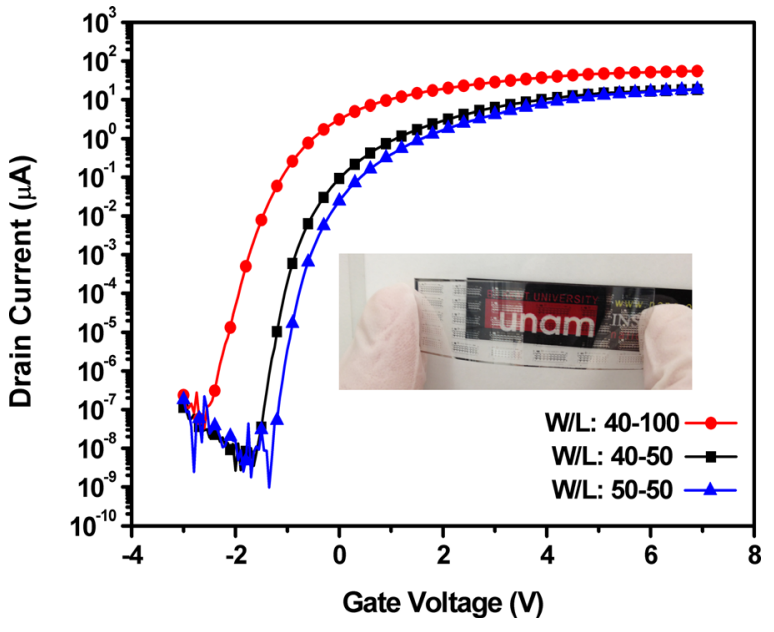

FIG. 5. (Color online) $\mathrm{I}_{\mathrm{D}}-\mathrm{V}_{\mathrm{GS}}$ characteristics of devices having different channel length and width values fabricated on PET substrates.
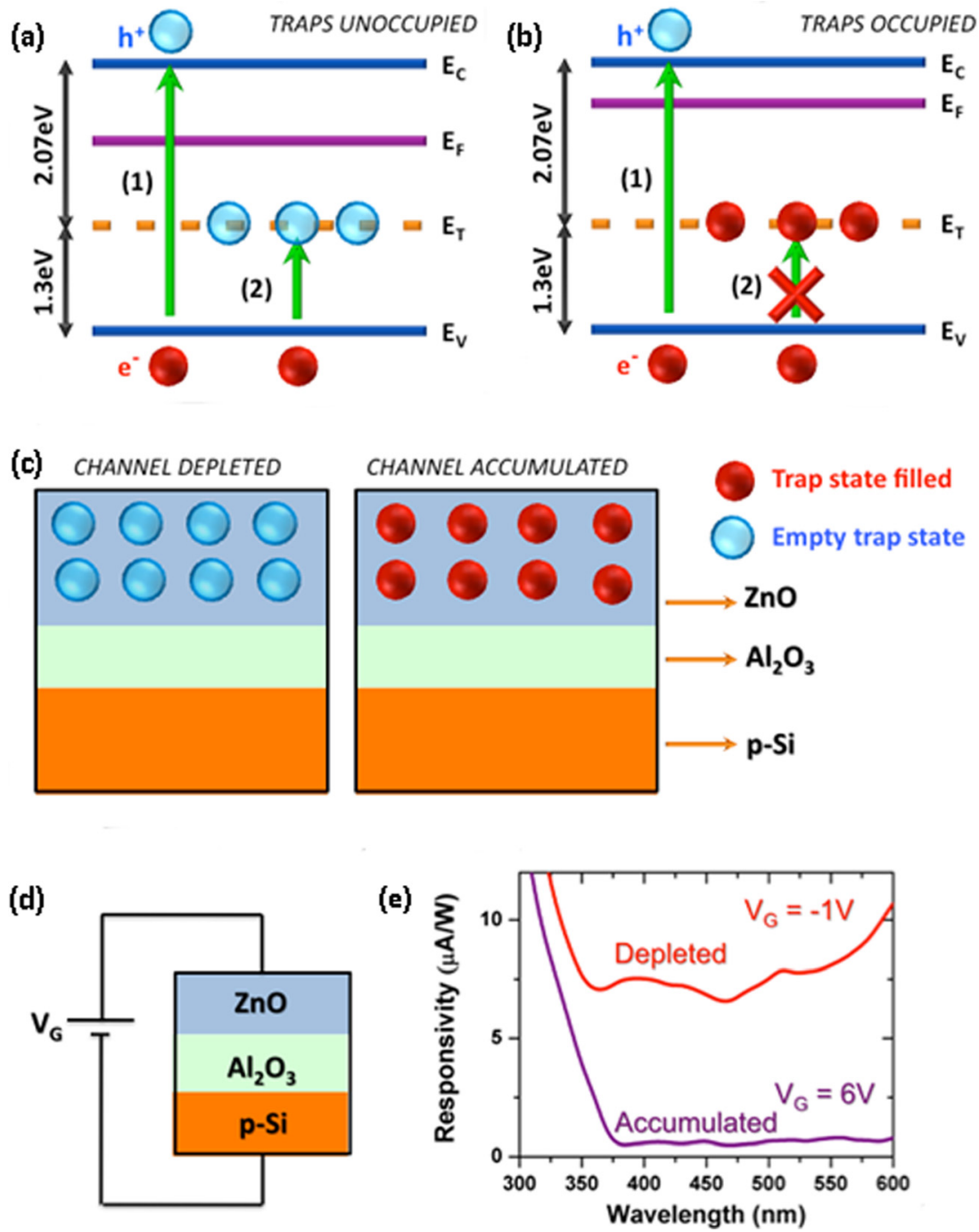

FIG. 6. (Color online) Trap related optical characteristics of $\mathrm{ZnO}$ deposited at $80^{\circ} \mathrm{C}$. Energy band diagram depicting trap states (a) unoccupied and (b) occupied by an electron. Band-to-band (1) and valence band-to-trap state (2) absorption mechanisms are shown by arrows. When the traps are occupied, second transition is suppressed. (c) Illustration of the MOS gate sketch of TFT devices comprised of p-Si/Al ${ }_{2} \mathrm{O}_{3} / \mathrm{ZnO}$. ALD-grown $\mathrm{ZnO}$ is the channel layer. (d) Applied gate bias voltage and measured spectral photoresponsivity at accumulated state $\left(\mathrm{V}_{\mathrm{G}}=6 \mathrm{~V}\right)$ and depleted state $\left(\mathrm{V}_{\mathrm{G}}=-1 \mathrm{~V}\right)$. 
where $\varepsilon_{\mathrm{r}}$ denotes dielectric constant of ALD deposited $\mathrm{Al}_{2} \mathrm{O}_{3}$ (taken as 9 in calculations ${ }^{18,19}$ ).

Electrical characteristics exhibit similar trend with XPS results. As growth temperature increases, $\mathrm{O} / \mathrm{Zn}$ ratio in the film decreases, which results in higher effective doping. ${ }^{20-23}$ At low deposition temperature, $\mathrm{O}-\mathrm{H}$ bonds passivate the defects and therefore reduce carrier concentration and increase $\mathrm{I}_{\mathrm{on}} / \mathrm{I}_{\text {off }}$ ratio. However, defects' detrimental effect on mobility is still present, which increases due to presence of hydrogen impurity scattering at low temperatures. It was proposed that oxygen vacancies and zinc interstitials are responsible for the $\mathrm{n}$-type behavior of $\mathrm{ZnO}$ films due to the creation of shallow donor levels below the conduction band of $\mathrm{ZnO}$. As a result, high $\mathrm{O}-\mathrm{H}$ concentration means high $\mathrm{O} / \mathrm{Zn}$ ratio, which results in less unintentional doping concentration. ${ }^{13}$

Flexible ZnO TFT devices are fabricated using films grown at $80^{\circ} \mathrm{C}$, since $80^{\circ} \mathrm{C}$-growth results in the highest $\mathrm{I}_{\mathrm{on}} /$ $\mathrm{I}_{\mathrm{off}}$ ratios and the lowest subthreshold slopes. $\mathrm{I}_{\mathrm{D}}-\mathrm{V}_{\mathrm{GS}}$ characterization results showed that devices on different substrates (Si and PET) show similar electrical behavior. Flexible devices, which have a channel length of $40 \mu \mathrm{m}$ and channel width of $50 \mu \mathrm{m}$, have $\mathrm{I}_{\text {on }} / \mathrm{I}_{\text {off }}$ ratio on the order of $10^{8}$. Subthreshold slope of flexible TFTs with the same channel dimensions is found to be $0.142 \mathrm{~V} / \mathrm{dec}$, which is also similar to that of the device, built on Si substrate. Electron mobility and threshold voltage values are extracted as $8.40 \mathrm{~cm}^{2} / \mathrm{V} \mathrm{s}$ and $-0.23 \mathrm{~V}$, respectively (see Fig. 5).

\section{B. Optical characterization of ZnO TFTs}

Crystal defects in $\mathrm{ZnO}$ create energy states in the forbidden band gap of $\mathrm{ZnO}^{24}$ Spectral photoluminescence (PL) characteristics obtained from 42-nm-thick $\mathrm{ZnO}$ layer deposited at $80^{\circ} \mathrm{C}$ on double side polished quartz revealed that $\mathrm{ZnO}$ film has a broad PL spectrum centered around $600 \mathrm{~nm}$ $(2.07 \mathrm{eV}){ }^{8}{ }^{8}$ Through these defect states, $\mathrm{ZnO}$ can absorb photons with energy lower than its bandgap energy $(3.37 \mathrm{eV})$. Such a sub-bandgap transition could occur through the excitation of an electron from valence band to trap state (transition 2 in Fig. 6) and from trap state to conduction band (not shown in Fig. 6). To excite electrons from valence band to trap state (transition 2), an unoccupied trap state is required.

To investigate sub-bandgap photosensing properties of $\mathrm{ZnO}$ based TFTs, devices are illuminated from the top $(\mathrm{ZnO})$ side with a mechanically chopped $(395 \mathrm{~Hz})$ monochromatic light. The photogenerated current is measured using a lock-in amplifier. Visible light absorption of $\mathrm{ZnO}$ based TFTs can be actively controlled by external gate bias as shown in Fig. 6. When strong negative gate bias is applied, electrons are depleted from $\mathrm{n}-\mathrm{ZnO}$ channel region. The number of unoccupied trap states and hence the probability of sub-band gap photon absorption will increase. On the other hand, as more positive gate bias is applied, electrons are accumulated to the channel layer, number of unoccupied traps and probability of sub-band gap absorption will decrease.

\section{CONCLUSION}

We present the effect of channel layer growth temperature on the electrical characteristics of bottom-gate $\mathrm{ZnO}$ TFTs. The effective carrier concentration and hence the electrical properties of TFTs are strongly influenced by $\mathrm{ZnO}$ deposition temperature. Functional TFTs on flexible substrates based on ALD-grown $\mathrm{ZnO}$ films are also demonstrated. Furthermore, we demonstrated the dynamic control of light absorption in ALD-grown ZnO TFTs. Electrical tuning of the optical response of $\mathrm{ZnO}$ based TFTs to visible light is experimentally verified and explained by the occupancy of deep level traps in $\mathrm{ZnO}$ films.

\section{ACKNOWLEDGMENTS}

This work was supported by The Scientific and Technological Research Council of Turkey (TUBITAK) under Grant Nos. 109E044, 11A015, 112M004, 112E052, $112 \mathrm{M} 482$, and 113M815.

${ }^{1}$ D. Kim, H. Kang, J. M. Kim, and H. Kim, Appl. Surf. Sci. 257, 7906 (2011).

${ }^{2}$ N. Huby, S. Ferrari, E. Guziewicz, M. Godlewski, and V. Osinniy, Appl. Phys. Lett. 92, 023502 (2008).

${ }^{3}$ E. M. C. Fortunato, P. M. C. Barquinha, A. C. M. B. G. Pimentel, A. M. F. Gonçalves, A. J. S. Marques, L. M. N. Pereira, and R. F. P. Martins, Adv. Mater. 17, 590 (2005).

${ }^{4}$ E. Fortunato, P. Barquinha, A. Pimentel, A. Gonçalves, A. Marques, L. Pereira, and R. Martins, Thin Solid Films 487, 205 (2005).

${ }^{5}$ R. L. Hoffman, B. J. Norris, and J. F. Wager, Appl. Phys. Lett. 82, 733 (2003).

${ }^{6}$ Y. Kawamura, M. Horita, Y. Ishikawa, and Y. Uraoka, in Proceedings of the 19th International Workshop on Active-Matrix Flatpanel Displays and Devices (AM-FPD) (2012), pp. 179-182.

${ }^{7}$ P. F. Carcia, R. S. McLean, M. H. Reilly, and G. Nunes, Jr., Appl. Phys. Lett. 82, 1117 (2003).

${ }^{8}$ L. E. Aygun, F. B. Oruc, F. B. Atar, and A. K. Okyay, IEEE Photonics J. 5, 2200707 (2013).

${ }^{9}$ A. Ohtomo and A. Tsukazaki, Semicond. Sci. Technol. 20, S1 (2005).

${ }^{10}$ M. D. Barankin, E. Gonzalez II, A. M. Ladwig, and R. F. Hicks, Sol. Energy Mater. Sol. Cells 91, 924 (2007).

${ }^{11}$ J. B. Lee, H. J. Kim, S. G. Kim, C. S. Hwang, S. H. Hong, Y. H. Shin, and N. H. Lee, Thin Solid Films 435, 179 (2003).

${ }^{12}$ J. H. Lee, K. H. Ko, and B. O. Park, J. Cryst. Growth 247, 119 (2003).

${ }^{13}$ S. Kwon et al., Semicond. Sci. Technol. 24, 035015 (2009).

${ }^{14}$ J. H. Kwon, J. H. Seo, S. Shin, and B. K. Ju, J. Phys. D: Appl. Phys. 42, 065105 (2009).

${ }^{15}$ E. M. C. Fortunato, P. M. C. Barquinha, A. C. M. B. G. Pimentel, A. M. F. Gonçalves, A. J. S. Marques, R. F. P. Martins, and L. M. N. Pereira, Appl. Phys. Lett. 85, 2541 (2004).

${ }^{16}$ S. Masuda, K. Kitamura, Y. Okumura, S. Miyatake, H. Tabata, and T. Kawai, J. Appl. Phys. 93, 1624 (2003).

${ }^{17}$ J. Siddiqui, E. Cagin, D. Chen, and J. D. Phillips, Appl. Phys. Lett. 88, 212903 (2006).

${ }^{18}$ J. Koo, J. Lee, S. Kim, Y. D. Kim, H. Jeon, D. S. Kim, and Y. Kim, J. Korean Phys. Soc. 47, 501 (2005).

${ }^{19}$ M. J. Biercuk, D. J. Monsma, C. M. Marcus, J. S. Becker, and R. G. Gordon, Appl. Phys. Lett. 83, 2405 (2003).

${ }^{20}$ E. Guziewicz et al., Microelectron. J. 40, 293 (2009).

${ }^{21}$ S. J. Pearton, D. P. Norton, K. Ip, Y. W. Heo, and T. Steiner, Superlattices Microstruct. 34, 3 (2003).

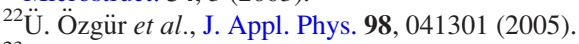

${ }^{23}$ C. Klingshirn, Phys. Status Solidi B 244, 3027 (2007).

${ }^{24}$ E. Guziewicz et al., Semicond. Sci. Technol. 27, 074011 (2012). 